\title{
PRÁCTICAS PROFESIONALES DEL SEXO: EL SABER DE LAS TRABAJADORAS SEXUALES EN LAS CALLES DE IQUIQUE
}

\author{
PROFESSIONAL PRACTICES OF SEX: THE KNOWLEDGE OF SEX WORKERS IN \\ THE STREETS OF IQUIQUE
}

\author{
Jacqueline Espinoza-Ibacache $e^{1}$ y Lupicinio Íñiguez-Rueda ${ }^{2}$
}

\begin{abstract}
En el presente artículo identificamos las denominaciones, definiciones y modos de hacer de las mujeres que ejercen prácticas profesionales del sexo en las calles de Iquique. Para ello, consideramos la perspectiva etnometodológica que centra su interés en los métodos empleados por las actrices sociales para producir los escenarios sociales en los que participan y, una etnografía que contempló observaciones y entrevistas en profundidad a trabajadoras sexuales de las calles de la capital de la Región de Tarapacá Chile. Argumentamos que estas actrices sociales denominan a las prácticas profesionales del sexo como un trabajo, sin embargo, las acciones moralizantes y jurídicas del contexto contribuyen a que se defina como una práctica social deslegitimada. Dicha definición repercute en sus modos de hacer respecto al manejo de sus relaciones familiares, gestión del espacio público y privado, relaciones de género, usos del lenguaje. Al focalizarnos en la producción de estrategias y procedimientos diminutos, situados que les permiten resistir a estas trabajadoras cotidianamente, no pretendemos normalizar su precariedad, sino más bien señalar que su agencia nos brinda un punto de vista privilegiado sobre cómo desafiar los límites de patrones hegemónicos que definen lo femenino.
\end{abstract}

Palabras claves: trabajo sexual, actrices sociales, normas en uso, prácticas sociales, etnometodología.

In the present article we identify the denominations, definitions and ways of doing of women who practice professional sex in the streets of Iquique (the capital of the Tarapacá Region, northern Chile). We have adopted an ethnomethodological perspective, which focuses on the methods used by social actresses to give meaning to their actions, to carry out an ethnography that included observations and in-depth interviews with sex workers from the streets of Iquique. We argue that these social actresses refer to professional sex practices a work; however, the moralizing and legal actions of the context contribute to their being defined as a delegitimized social practice. This definition has an impact on these sex workers'ways of doing things regarding the management of their family relationships, the management of public and private space, gender relations, and uses of language. By focusing on the production of tiny strategies and procedures, which allow these workers to resist on a daily basis, we do not intend to normalize their precariousness, but rather to point out that their agency gives us a privileged point of view on how to challenge the limits of hegemonic patterns that define the feminine.

Key words: Sex work, social actresses, norms in use, social practices, ethnomethodology.

Al llegar a visitar a las mujeres de "Bolívar", en referencia al nombre de la calle donde mujeres con mayoría de edad y de edades diversas realizan prácticas profesionales de sexo $^{1}$, divisamos un furgón de la policía uniformada detenido en medio de la calle y a sus funcionarios arrestando a dos mujeres negras que cada día ocupan 'su' esquina. Justo frente a portones de las únicas empresas instaladas en esta zona, y que son solo ocupadas durante el día por sus trabajadores, ellas y sus compañeras provenientes mayoritariamente de Colombia, algunas de Bolivia, Perú, Paraguay y unas pocas de Chile esperan a sus clientes vestidas de manera 'informal' para el imaginario del contexto social -sin tacones o vestimenta escotada- con zapatos bajos, pantalones o faldas cortas dependiendo de la estación del año y tenue maquillaje.

Esta zona de la calle Bolívar con residencias y empresas, está localizada específicamente a dos manzanas al norte del centro, aún en el casco antiguo de Iquique. Estamos en la capital de la Región de Tarapacá, la que se ha erigido como una localidad atrayente para la migración internacional en el

\footnotetext{
${ }^{1}$ Programa de Doctorado "Persona y Sociedad en el Mundo Contemporáneo", Departamento de Psicología Social, Facultad de Psicología, Universidad Autónoma de Barcelona. Barcelona, España. jacqueline.espinoza.ibacache@gmail.com

2 Departamento de Psicología Social, Facultad de Psicología, Universidad Autónoma de Barcelona. Barcelona, España. lupicinio.iniguez@uab.cat
} 
contexto chileno, producto de un desarrollo económico estable, su localización en la frontera norte de Chile que la hace cercana a otros países de la región y sus características climáticas intertropicales (Contreras Gatica y Palma Calorio 2015). Sin embargo, la llegada de inmigrantes se ha vinculado con el fomento de prácticas profesionales del sexo al tiempo que se ha invisibilizado su carácter histórico que proviene del periodo de la industria del salitre de finales del siglo XIX y comienzos del siglo XX (Pavez 2011).

Vemos que sus esquinas no están tan iluminadas como el resto de sus calles. En los primeros meses del 2013 había un cártel colgado en una de las esquinas utilizadas por estas mujeres, producto de una campaña de la organización vecinal, que reclamaba que la presencia de las mujeres migrantes afrocolombianas causaba desordenes y estimulaban la violencia del sector (Oñate Rojas 2013). El cartel ocupaba en su primera oración un fragmento de su himno que decía: "Iquiqueños arriba la frente, no más prostitución, recuperemos nuestros barrios" mientras la imagen de fondo era la silueta de una familia tradicional heteronormativa: un hombre y mujer tomando de los brazos a un niño. El uso de la frase del himno iquiqueño -que tocan todos los mediodías en la radio municipaloperaba como una arenga que interpela a un "nosotros" y simultáneamente, situaba a la prostitución como una práctica externa y responsable del presente deteriorado en las distintas esferas de la sociedad iquiqueña.

El cartel ya no está, lo que sí quedó fue una ordenanza promulgada por la administración local ese mismo año que zonifica para esta actividad un sector específico en la periferia de la ciudad. Esta zonificación está amparada en un decreto establecido en el siglo XIX que permite que las municipalidades ordenen su espacio público sobre la base de la defensa de la moral y las buenas costumbres (Ministerio del Interior 1891). La represión policial que vimos al llegar es producto de este mandato que resguarda a la ciudadanía de estas actrices sociales y sus prácticas -inoportunas y prohibidas- $\mathrm{y}$, en este caso, mediante la higienización del espacio público. Una ordenanza que no prohíbe su actividad, sino que las exilia a un sitio eriazo en los límites de la urbe, que no consideró los discursos de estas mujeres en su diseño, que no estipula umbrales -al menos- de seguridad y que nos recuerda a los decretos establecidos para contrarrestar los "males de trascendencia social" en los primeros decenios del siglo XX. Sin embargo, ellas continúan captando clientes en los intersticios que surgen entre el ir y venir de las patrullas de las policías civil y uniformada en esas mismas calles. Así lo observamos al dejar atrás a las fuerzas del orden para avisar sobre su presencia a las que aún estaban en las esquinas siguientes. Al escucharnos, estas mujeres corrieron hacia otras calles donde podrían pasar desapercibidas y evitar así las sanciones criminales.
En Chile, desde sus primeros años, el Estado moderno ha definido a las prácticas profesionales del sexo como transgresiva y si bien estas prácticas son anteriores a este periodo, fue a partir de esta etapa que comenzó a tener mayor notoriedad, adquiriendo significados asociados al problema social y de identidad (Walkowotz 1993). Por un lado, estas normas, al proscribir ciertos comportamientos en referencia a un rol femenino hegemónico, influyen en los que sí son permitidos lo que implicaría la imposición de ideales sociales y morales de lo que debe ser y hacer "la" mujer para pertenecer a la sociedad dominante. Podríamos decir que esto nos habla no solo de cómo son definidas ciertas prácticas sociales, sino también, y principalmente, de la sociedad dominante, en relación a qué actrices sociales e instituciones producen alteraciones y cómo se regula para que se instaure el orden.

Por otro lado, la desobediencia de las profesionales del sexo no solo a las normas jurídicas, sino a las morales y sociales, nos plantea una manera distinta de actuar en torno a los patrones hegemónicos impuestos que señalan que las mujeres deben cuidar su hogar, postergar sus intereses por los demás y mantener estrictamente controlada su sexualidad (Juliano 2017). No obstante y en lugar de dar cuenta de estos saberes, omitimos su conocimiento práctico, desconocemos sus modos de hacer o reapropiaciones de los imaginarios que las marginan. Más aún, frecuentemente establecemos categorías y nociones estigmatizantes y ajenas a su contexto que no han hecho más que reforzar cierto orden social.

Como una manera de contribuir en la producción de un conocimiento contextualizado, que desvincule a estas mujeres de categorías y discursos dominantes que reproducen estereotipos, en el presente artículo identificaremos las denominaciones, definiciones y modos de hacer de las mujeres que ejercen prácticas profesionales del sexo en las calles de Iquique, mediante la producción situada de sus escenarios sociales y reconstruyendo inductivamente las categorías y estrategias que producen y emplean en su realidad social.

\section{Actrices Sociales que Saben lo que Hacen}

Un importante número de literatura enfocada en problematizar las prácticas profesionales del sexo como una actividad laboral que podrían ejercer las mujeres se ha producido en las últimas décadas. Hablan sobre la conceptualización de la prostitución o trabajo sexual, pero la elección de su denominación no es neutral pues dará lugar de facto a distintas prácticas sociales que les darán un carácter constituyente y marcan controversias teóricas, éticas y políticas, principalmente dentro de las perspectivas feministas.

Así por ejemplo, las feministas se mueven entre dos polos, las abolicionistas que adoptan el término 
"prostitución", la definen como esclavitud sexual y una cuestión de desigualdad de género (de Miguel Álvarez y Palomo Cerdeño 2011; Gimeno 2012), y las que se denominan pro-derecho, que utilizan el término "trabajo sexual" y lo entienden como una actividad laboral que debería tener derechos de seguridad y protección social (Lamas 2016; Pheterson 2000 [1996]). Entendemos que las distintas perspectivas buscan comprender esta práctica social, que bien sabemos, está repleta de controversias, sentimientos, sentidos y significados (Graça y Gonçalves 2015). Sin embargo, y como dijimos en la introducción, en la búsqueda de dicha comprensión frecuentemente se establecen categorías ajenas al contexto de las mujeres que ejercen esta actividad; o como dice María Dolores Juliano al referirse a las investigaciones acerca de estas actrices sociales, se "habla sobre ellas pero sin escucharlas" (Juliano 2005:83). Simultáneamente se produce un tipo de conocimiento que tradicionalmente se entiende como especializado o erudito y, por tanto, considerado como superior a otros e incluso al de las mismas mujeres que ejercen las prácticas profesionales del sexo.

La Etnometodología (Garfinkel 1967) representa una aportación significativa en la cuestión de la producción de un conocimiento que hable desde ellas y con ellas, al señalar que el actor o actriz social sabe qué es lo que hace y tiene métodos para organizar su cotidianeidad. Contribuye también a ello cuando critica el estatus de la producción científica mediante la problematización de la objetivación de lo social como privilegio de la ciencia, replanteándolo como un tipo de conocimiento práctico, o sea, una "facultad de interpretación que todo individuo, erudito o profano, posee y pone en práctica en la rutina de sus actividades prácticas cotidianas" (Coulon 1987:57). De modo que el conocimiento práctico de estas mujeres no se distinguiría del conocimiento científico porque todas somos capaces de describir, hablar y configurar nuestra propia realidad social.

De ahí la frase del subtítulo. Cuando señalamos "actrices sociales que saben lo que hacen", nos hacemos eco de la crítica que realiza la Etnometodología a la Sociología que marginaba el conocimiento de los actores y actrices sociales en el enfoque analítico de la acción social. Como es sabido, desde esta perspectiva se problematiza el paradigma estructural-funcionalista y revaloriza el enfoque micro-sociológico a través del análisis de la vida cotidiana (Martínez-Guzmán et al. 2016), centrando su interés en los métodos compartidos por los actores y actrices sociales y así identificar "cómo fabrican un mundo razonable para vivir en él" (Coulon 1987:34).

Es de esta manera que se aleja del predominio de las estructuras sociales como fuente externa de coerción y constricción de las actrices o actores sociales, lo que no quiere decir que se desestimen. Más bien, está atenta a cómo ellas racionalizan, se adaptan y ajustan a éstas, justamente porque las estructuras o normas no hablan por sí mismas, sino que solo lo hacen en conexión con su contexto (Wolf 1982). En este sentido, estas mujeres tienen un rol fundamental en la producción de su orden social, pues será es el resultado de sus realizaciones prácticas (Garfinkel 1967; Heritage 1991).

Estas realizaciones prácticas se asocian a la membresía competente ${ }^{2}$, es decir, al manejo que las actrices sociales tienen no solo del conocimiento, sino también de los procedimientos que operan de manera tácita y cotidiana, pues le permiten participar en la definición "desde dentro" de sus contextos sociales (Íñiguez 2006). También le otorga importancia al lenguaje, ya que la inteligibilidad del discurso de las actrices competentes tendrá relación con sus propiedades indexicales. Lo que esto quiere decir es que el significado de sus palabras depende de su contexto de producción por lo cual, para su comprensión, es preciso recurrir a las condiciones de uso ordinario y del espacio social en donde se desarrolla su enunciación (Garfinkel 1967). De este modo, se aleja de la concepción únicamente representativa del lenguaje y subraya su carácter situado y contingente para la comprensión de su proposición. Además, el lenguaje también es constitutivo, pues las actrices sociales al hablar de sus asuntos cotidianos simultáneamente y en movimiento bidireccional que opera en cada momento, constituyen reflexivamente el sentido, la racionalidad y el orden de estas acciones (Coulon 1987). Por ello, resultan importantes las explicaciones, o accountability, de las acciones susceptibles de ser describibles, inteligibles y analizables, en este caso de las mujeres que ejercen prácticas profesionales del sexo en su contexto social.

Con este marco etnometodológico, realizamos una investigación de tipo etnográfico de las acciones cotidianas con las mujeres que ejercen prácticas profesionales del sexo en las calles de Iquique, con el fin de producir un conocimiento contextualizado de su quehacer. Para facilitar nuestra inserción en la ciudad nortina, contactamos a Gertrudis, mujer de 68 años, ex profesional del sexo y activista de la Fundación Margen en Iquique, una organización que promueve los derechos de mujeres trabajadoras sexuales desde el año 1998 (Observatorio de Políticas Públicas en VIH y SIDA 2012).

Con la colaboración de Gertrudis y aproximadamente otras 200 mujeres con edades que fluctuaban entre 20 a 68 años, procedentes de diversos países como Chile, Colombia, Perú, Paraguay, Bolivia, realizamos nuestro trabajo de campo durante seis meses en el año 2015. Siguiendo las directrices éticas marcadas por la Universitat Autònoma de Barcelona (UAB) ${ }^{3}$, 
realizamos observaciones de la cotidianeidad de las prácticas sexuales ejercidas en las calles de Iquique, entre cliente y cliente les preguntamos a estas mujeres sobre la realización de una entrevista. Fue a medida que nos hicimos reconocibles en estas calles que las primeras aceptaron y ellas nos contactaron con sus compañeras, utilizando la "técnica de bola de nieve" (Taylor y Bogdan 1996) entrevistamos a doce colombianas y dos chilenas profesionales del sexo. A continuación abordaremos el análisis que articulan a las entrevistas y las anotaciones de nuestro cuaderno de campo realizadas en las calles de Iquique, los diálogos establecidos con los textos escritos por activistas pro derecho, trabajadoras sexuales o académicas, entre otros actores y actrices sociales de este campo-tema (Spink 2005).

\section{La “Oficina”: Pararse en la Esquina}

Es noviembre del 2015, Celia, de 31 años y proveniente de Colombia, nos dice: "tengo que comer antes de ir a la "oficina”", mientras se dirige al restaurante que vende comida de su país y al que va regularmente antes de ir a trabajar. "La oficina" como llama a 'su' esquina donde espera de lunes a sábado a los clientes a los que les presta servicios sexuales, se ubica en un sector de calles con nombres de hombres que en los libros de historia llaman Libertadores de Sudamérica como San Martín y Bolívar, y que interceptan de este a oeste con arterias con nombres de héroes de la Guerra del Pacífico como Amunátegui, Barros Arana o Vivar, respectivamente.

Si caminamos por las siguientes calles en dirección al oeste de este sector, nos encontraremos con el colectivo de mujeres transexuales que ejercen también prácticas profesionales del sexo. La calle marca la frontera del territorio apropiado por cada grupo. Nos los dice Clara, una profesional del sexo iquiqueña de 32 años, que se ubicó en el sitio equivocado al llegar a trabajar a la calle por primera vez hace un año y dos meses: "Vine en la noche al sector donde están los travestis y ellos mismos me mandaron donde las colombianas. Y en las colombianas justo había otra chilena que me enseñó, así empecé a trabajar en la vida de noche...". No solo está la división de los dos sectores entre mujeres y mujeres transexuales que ejercen esta actividad, sino también el uso "donde las colombianas" que como expresión indexical refiere a cómo este sector se ha caracterizado como propio y solo de estas mujeres, a pesar de haberlas de distintas nacionalidades. Así también lo publicaba el periódico local en el año 2012 al reportar la protesta de vecinos sobre el ejercicio del trabajo sexual en 'sus' calles, con la fotografía de una pancarta que decía: "No a la prostitución colombiana" (Rondón 2012).

"No tenía más nada qué hacer, entonces pregunté que donde las niñas se paraban, ya conocía a muchas de la "oficina", ya entonces, me aceptaron". Nos cuenta Juana, de 20 años y procedente del país cafetero, en la habitación de material ligero en la que hay solo una cama que comparte con tres personas, entre ellas su pareja o "Caramelo" como le dice ella, que entra y sale de la habitación. La calle fue su última opción. Antes había trabajado en un puesto de comida rápida por un sueldo inferior al mínimo con la promesa incumplida del contrato de trabajo que le permitiría la obtención del permiso de residencia; luego siguieron unos meses en un cabaret pero fue despedida al enterarse sobre su irregularidad migratoria. Entretanto, su madre que vive de sus remesas y que le cuida a su hija en Cali, aún cree que ella trabaja en el puesto de comida rápida.

Clara, que también había tenido distintos trabajos que no le permitían suplir sus necesidades de subsistencia, nos dice "un día no tenía pa" comprar pan y me vine a pararme acá". Separada del padre de sus tres hijos que no le entregaba manutención, ya había tenido un acercamiento al "ambiente" cuando trabajaba en una cafetería -como ella le llama- que clandestinamente tenía espacios privados para atender a los clientes que deseaban servicios sexuales. Nos dice que lo que menos se vendía era café, sí bebidas alcohólicas, como prosigue Clara: "es que había que tomar, y uno después, uno aprendió a jalar y después uno toma otros vicios", quiso salir de este círculo porque sus hijos crecían y se darían cuenta de lo que estaba haciendo su mamá. Entretanto, ellos están al cuidado de su abuela y creen que el trabajo de Clara en la "cafetería" alcanza para pagar los estudios universitarios de su hija mayor.

Vemos que los hombres -a menudo en grupo- al llegar a las "oficinas" disminuyen la velocidad para gritarles alguna insolencia que poco se entiende pero sí sus carcajadas permanecen en el ambiente. Ellos visibilizan materialmente la transgresión moral sexual en su cotidianeidad. Nos dice Rosa de 23 años, procedente de Colombia que trabaja intermitentemente en las calles y schoperías ${ }^{4}$ desde hace un año, que:

La otra vez estábamos ahí para'a, entonces iban unos chilenos y ¿qué?... nos dicen: 'ven maraca culiada', que me dijeron, ahí con la gordita, ¿te acuerdas de la gordita? (yo asiento con la cabeza y ella continúa el relato). Nos dijeron así y ¿por qué?, es que maraca en Colombia son esas que hacen de instrumento, que suenan. Veníamos recién llegando a la esquina.

Estos hombres intentaban ofenderla, en Chile esa expresión soez se utiliza para calificar el trabajo sexual $\mathrm{y}$, especialmente para calificar despectivamente a una persona sexualmente promiscua. Se puede identificar, en esta forma de relacionarse con las mujeres que 
ejercen este oficios aspectos normativos y sobre todo morales asociados al orden hegemónico. En tanto, las trabajadoras colombianas no comprendieron la propiedad indexical de la frase, sino que la asociaron al instrumento musical. El tiempo transcurrido en las calles permite que Rosa ahora entienda el significado y el sentido de la frase y por lo mismo lo relata cuando le preguntamos si los insultos son recurrentes.

A partir de junio del 2013, también la ordenanza municipal forma parte de su contexto, pero especialmente como una constante para las mujeres migrantes que ejercen esta actividad, pues las chilenas no señalan persecuciones policiales. Sus compañeras provenientes de otros países corren a esconderse para sortear el control, como nos cuenta Eloísa:

...estamos toda la noche corriendo, nooo, sí una no la... que no la corretearán disminuiría el estrés de uno, solo aunque no nos corretearán, pero imagínese, todos los días como si uno estuviese robando y la PDI [Policía de Investigaciones de Chile] detrás de uno. Usted viera (se le llenan los ojos de lágrimas y se le quiebra la voz)... Nos hacen sentir como delincuentes, nooo, peor que los delincuentes porque yo creo que ni a los delincuentes los corretean así, peor.

Ella es colombiana y tiene 23 años, hace seis meses que está presenciando este "correteo" de la policía en las calles; se ha caído en más de una ocasión, raspándose las rodillas y pegado en la cabeza en la búsqueda de un escondite; más de alguna vez la alcanzaron y terminó durmiendo en el calabozo. Si el trabajo sexual de calle no está prohibido en Chile, conviene preguntarnos ¿qué se prohíbe al focalizar su control en las mujeres migrantes afrodescendientes que ejercen el trabajo sexual de calle? ¿Qué pautas de convivencia amenazan estas mujeres en estos espacios públicos?

Eloísa buscó otro empleo en el que lleva una semana y "ya de aquí a dos meses ya no regreso más, no, porque tengo mi pega normal". En el corto periodo de doble jornada laboral que ha transcurrido, descansa desde el atardecer hasta la medianoche en la habitación que comparte con Juana y "Caramelo", así ahorra de alguna manera dinero para enviárselo a su madre que cuida a su hija, también, en Cali. "Cuando llegué de Colombia trabajé primero decentemente, pero la paga era muy mala", dice Celia, que tuvo "una pega normal" como dice su compatriota Eloísa o "decente" como ella misma señala. Estas mujeres a través de estos calificativos distinguen implícitamente al trabajo sexual aludiendo a su carácter reprobable en torno a las transgresiones al orden social y moral. ¡Motivos tienen! Como nos dice Eloísa, "si lo dejarán tanto de señalar a uno y corretearlo, como lo correteen, uno haría el trabajo como algo que sale, se vería como algo positivo, pero no en las condiciones en que estamos, noooo".

\section{¿Vamos a Compartir un Ratito?}

"Trabajo desde las 9 hasta las 11:30 a 12 de la noche, igual aunque me vaya bien o me vaya mal, igual me voy, igual siempre me hago dos o tres servicios", nos dice Clara que ha instaurado una rutina asociada a horas y clientes. También sus compañeras tienen sus horarios, las que llegan más tarde trabajarán hasta las 2 de la madrugada los días de semana y los fines de semana que "es más bueno" lo harán una o dos horas más, dependiendo de la afluencia de clientes.

Tanto Clara, como Juana saben que no es llegar e instalarse en una "oficina" porque hay reglas que cumplir: "las niñas que llegan ahí, es porque viene invitada. Si yo ya llevo tiempo y voy a llevar a una, claro que sí la aceptan porque ya tengo tiempo, pero sino tengo el tiempo a mí me sacan al tiro [de inmediato]". Juana nos señala que la antigüedad en la esquina es requisito para invitar, ella llegó porque tenía una amiga que le sirvió de aval y unos meses después también llevó a alguien trabajar allí. En tal sentido es que hay una apropiación y organización del uso de las esquinas generada a través de su acceso restrictivo, que nos recuerda a la división de las calles respecto al colectivo de mujeres transexuales.

Gabriela es chilena, llegó al igual que Juana por medio de una amiga, una vez que decidió abandonar el cabaret "de un día para otro, dije no, esto no es conmigo, mi hijo está creciendo y me va ver que ando toda cura' a [borracha], nunca en peleas, ni en problemas, sipo, pero me gustaba tomar, a parte que... ganaba tomando, po". Madre soltera de ahora 56 años, comenzó a trabajar en el "ambiente" porque no tenía qué darle de comer a su hijo de entonces cuatro años, que ahora es un hombre de 33 años. Sin embargo, Gabriela no es el nombre que eligieron sus progenitores o el que usa en la cotidianeidad de su vida privada, sino que adoptó uno nuevo para disociar su vida personal y laboral. Lo aprendió una vez que esto se mezcló.

Me puse ese nombre, porque yo un día andaba con mi mamá y mi hermana, y un gallo [hombre] desubicado de una esquina a la otra me gritó: "(Nombre propio) va a estar allá a la noche para ir a verte”. Y yo miré así, mi mamá miró, ellas sabían. Pero... iQué desubicado para gritarme eso!, sabiendo que voy con una señora, que voy con una niña. Entonces ya no le contesté nada, después en la noche cuando lo vi, lo reté bien retado, yo dije no, de aquí en adelante me cambio de nombre, total si voy 
con alguien y me gritan en la calle "Gabriela", no sabrán que me llaman a mí.

Ella recuerda la mirada de su madre y hermana al relatarnos la escena, para luego distinguirlas y excluirlas del lugar donde ella estará "a la noche" a través de una posición social impropia a esas lides: "una señora y una niña". El sujeto evidencia su labor, ellas la conocen, sin embargo es la exposición al frente de personas cercanas y ajenas a esta actividad lo que le produce indignación. Entonces ¿cómo actuar ante este "desubicado" -y los que puedan seguir- que al decir su nombre la expone a personas que son ajenas a este espacio y en un espacio ajeno a su actividad? Elige un seudónimo que permita resguardarse y cuidar su mundo privado, una práctica que adoptan las mujeres que ejercen esta actividad que, al igual que Gabriela, inventan una nueva identidad como estrategia para conservar su anonimato.

Mientras conversamos con mujeres que tienen nombres dependiendo de su escenario social, vemos que transitan los clientes, a veces en automóviles y otras veces caminando, siendo éstos últimos los menos. Vemos que los conductores desaceleran al pasar por la esquina, a veces llaman a algunas de las mujeres para solicitar sus prácticas o ellas toman la iniciativa al ver que el vehículo pierde velocidad. Ellos se detienen y las llaman. Ellas rápidamente analizan al eventual cliente y deciden si quieren comenzar la negociación. Si se decide hará contacto visual con el cliente y se acercará hasta donde esté situado. Como nos dice Rosa: "¿vamos a compartir un ratito?, eso es lo que uno dice. Y el otro dice: sí, ¿qué tanto me haría? y empiezan así... [...]...nosotros acordamos el precio y eso está por el servicio, una dice no más 'la básica', porque es así'. Cuando Rosa llegó a la esquina, sus compañeras de "oficina" le enseñaron que en este primer encuentro se negocia cómo, por cuánto y dónde porque no se deja nada al azar. También, le enseñaron algunas pautas de interacción, por ejemplo que se dice "vamos a compartir un ratito" para ofrecer servicios sexuales, que al decir "la básica" señalan el coito vaginal, que es el servicio más solicitado junto a la "francesa", como denominan al sexo oral.

Luego de la negociación, y si se decide subir al automóvil del cliente, utilizan estrategias para controlar lo que ocurre en este terreno incierto. Nos dice Elena: "ya la otra compañera mira la placa o la prima así pues, uno también le dice a la compañera 'oye mira la placa', pero le dice para que el cliente escuche, no es porque la otra le va a poner cuidado". Las historias sobre agresiones fluyen, "han acuchillado a una niña de ahî", que le robaron el teléfono móvil y el dinero que había ganado en el día, y así suma y siguen. Nos cuenta:

Eloísa:Fuiahacerunserviciodeacompañamiento, puta él me fue a tirar por allá, por la playa, por allá, me tuve que venir a pie de madrugada. Imagínese ese es un riesgo que una debe correr, uno no sabe que le puede pasar algo.

Investigadora: ¿Te dejaron allá?

Eloísa: Sí, él me dijo, te bajas, te bajas, te bajaaaas maraca cuali'a, te bajas, porque yo le hice una mamada, te bajas, te bajas y me dejó por allá tirada. Investigadora: ¿Habías hecho el servicio?

Eloísa: Sí, el servicio ya lo habíamos hecho, ya me había pagado pero me quería quitar el dinero, noo me dejé. Yo he pasado momentos muy malos en esta pega.

A ella la insultaron, intentaron golpearle y robarle $\mathrm{y}$, si bien pudo defenderse, permanece el miedo porque sabe que debe estar alerta, sabe que este episodio puede repetirse. Saben que estas prácticas se mantienen y se mantendrán impunes, ¿a quién reclamar sobre estas agresiones si la fuerza policial las persigue? Para evitar estos riesgos, han comenzado a utilizar otra zona de operaciones como estrategia para estabilizar su escenario social que estaba siendo alterado por estas agresiones. Celia que ha escuchado historias como las de Eloísa, nos dice: "a los autos no me subo, no voy, he escuchado muchas cosas de niñas que aparecen en el Marinero Desconocido"'. Así que voy a un hotel aquí cerca, al hotel Esmeralda". Ella ya no se sube a los autos así que luego de la negociación con el cliente se dirige caminando a dos hoteles cerca de sus esquinas, confían en que las cámaras del recinto registrará su ingreso y salida, también el de su compañero temporal.

Gabriela señala que los años de experiencia le han proporcionado una facultad para reconocer el tipo de cliente "será que uno está acostumbrada a trabajar con los hombres, que uno aprende a conocerlos, uno sabe al tiro [de inmediato] cuando está con la mala intención o no está con la mala intención, o te quiere intimidar solamente". Este saber le sirve para actuar de manera estratégica en situaciones complejas cuando reciben insultos. A pesar del mal trato, ellas reaccionan amablemente como una práctica de autocuidado. Es decir, se trata de una acción intencionada, un conocimiento práctico ganado en sus años de trayectoria laboral para mantener cierta estabilidad de su escenario laboral.

El ambiente es complejo. Sin embargo, nos dice Elena "hay mujeres que tienen sus clientes de años", lo que da cuenta de la heterogeneidad de relaciones en torno al intercambio económico-sexual, pues "hay veces que nos convertimos en la amante de los clientes, pero a veces hay personas que uno no conoce, igual po, y va más en el trato, cómo lo tratemos", nos detalla Clara. Ella como partidaria de tener clientes frecuentes, nos dice que les brinda un buen trato, les conversa, escucha para que la vuelvan a llamar; mientras Rosa nos dice "no doy número, yo les digo que no tengo y no tengo. Es que hay veces que uno está durmiendo y 
lo empiezan a llamar y así, aunque no tenga pareja, es que no me gusta". En este ir y venir de clientes, Clara y Rosa dan cuenta de sus realizaciones prácticas para organizar su trabajo.

En lo que sícoinciden es la dificultad para establecer el uso del preservativo sea éste un cliente frecuente o uno pasajero. "Cuesta mucho, mucho, si los hombres no quieren. Porque dicen, nooo, chi, con esta cuestión no se siente nada, yo vengo para acá porque quiero estar bien" nos relata Gabriela sobre las justificaciones que le dan sus clientes. A pesar de ello, ellas asumen el preservativo como una herramienta de trabajo, Clara les dice: "sin globos no hay cumpleaños, no más, sino te gusta te vas, porque llegará otro", y utiliza la analogía para señalar que sin preservativo no realizará el intercambio económico sexual convenido. Eso no quiere decir que los clientes estén a gusto con dicho elemento, frecuentemente implica una negociación, pues constantemente deben estar convenciéndolos que es una práctica de cuidado de salud sexual para ambos.

Luego de haber cumplido con las prácticas profesionales del sexo comprometidas con el compañero provisional, Clara, Gabriela, Juana vuelven nuevamente a su "oficina" donde esperará al próximo acompañante ocasional que acuda por su servicio.

\section{Discusión y Conclusiones}

Eloísa, Rosa y sus compañeras denominan a las prácticas profesionales del sexo como un trabajo. Sus prácticas sociales se vinculan con la competencia interaccional con sus clientes, un lenguaje que adorna sus acciones y el manejo de procedimientos propios. Es en este sentido que se estructuran modos de hacer y conocimientos que lo producen, organizan y estabilizan como un hecho social.

Modos de hacer que interactúan con las normas del contexto. Las normas jurídicas interfieren en los escenarios laborales de las mujeres -especialmentemigrantes, no como consecuencia de la internalización y constricción de su accionar, sino más bien, porque materializa las restricciones de clase, raza, etnia y género que les impone el Estado chileno. Su transgresión constante y sus efectos son parte de la norma en uso, paralelamente, la descripción de esta interacción produce reflexivamente críticas acerca de la criminalización de su actividad, la generación de un marco que sitúa a esta actividad fuera de la ley, su situación ciudadana y el desamparo institucional ante agresiones machistas en este escenario social.

Las normas morales actúan a través de la violencia machista. El campo semántico de las expresiones soeces e insultantes utilizadas por los clientes se puede comprender un tipo de moral que descalifica fuertemente el ejercicio del trabajo sexual y connota un tipo de actividad que transgrede su orden social. Y si bien, estas mujeres quebrantan esta norma pues asumen esta práctica como un trabajo, los insultos y la violencia son incluidos para describir su propia acción, planteándolo como parte de la racionalidad y especificidad de este escenario social.

Estas acciones moralizadoras y jurídicas contribuyen a que estas mujeres definan este trabajo como una práctica deslegitimada y que simultáneamente, se invisibilice sus condiciones económicas, raciales, migratorias que influyen en que ellas "se paren en las esquinas". No obstante, nos refieren la paradoja en el que habita este trabajo, estas mujeres se apartan del modelo de feminidad al transgredir la moral sexual dominante que juzga el pago remunerado de antemano por un intercambio económico-sexual, pero lo hacen con el objetivo de seguir otro patrón que la caracteriza, la supervivencia y cuidado de su grupo familiar.

Dicha definición repercute en sus modos de hacer respecto al manejo de sus relaciones familiares, gestión del espacio público y privado, relaciones de género y usos del lenguaje. Así es que guardan silencio de su trabajo a su familia. Adoptan un seudónimo para resguardar su anonimato y delimitar su escenario laboral de los otros en los que actúan. Estructuran las características, valoración económica, límites de sus prácticas entre las partes en un espacio público. Y utilizan un lenguaje propio con expresiones indexicales como "oficina", "pararse en la esquina" "compartir un ratito", "la básica", "sin globos no hay cumpleaños", cuya inteligibilidad y uso contingente le otorgan distinción a esta actividad, pero también adornan sus modos de hacer. Modos de hacer que no son estáticos pues se generan nuevos para resguardarse de contingencias que alteren la estabilidad de su actividad, como vimos cuando incluyeron la definición de un espacio específico para la realización de su trabajo en la negociación con los clientes, para disminuir los riesgos de agresiones machistas en sus actividades laborales cotidianas.

Si bien, es definida como una práctica deslegitimada, coincidimos con Juliano (2004) que plantea que el trabajo sexual no implica la peor opción considerando el espectro de posibilidades laborales poco apreciadas que tienen mujeres migrantes y de sectores menos favorecidos -tal como hemos observado- la diferencia reside en que éste está mal visto y mejor pagado. De ahí que las realizaciones prácticas que organizan el orden social del trabajo sexual de calle nos informa sobre las relaciones sociales heteropatriarcales, jerarquizaciones y conflictos en relación a la visibilización de la sexualidad de mujeres, pobres, negras y migrantes.

Finalmente, fijarnos en el "saber de las trabajadoras sexuales" permite ampliar el campo de los estudios de las prácticas profesionales del sexo produciendo un conocimiento que funcione en sentido inverso a 
categorías que estereotipan este quehacer. Estas mujeres inventan estrategias y procedimientos diminutos, frágiles, situados, que les permiten resistir cotidianamente a pesar de su contexto adverso. Con esto no pretendemos desdibujar su precariedad, más bien señalar que su agencia nos brinda un punto de vista privilegiado sobre cómo desafiar los límites de patrones hegemónicos que definen lo femenino.

Agradecimientos: Para la realización de esta investigación, la primera autora agradece el apoyo recibido de CONICYT, Chile, mediante, Beca de Doctorado en el extranjero del Programa de Formación de Capital Humano Avanzado. Igualmente agradecemos la colaboración de la Fundación Margen. Agradecemos muchísimo los comentarios de los y las compañeras del grupo "Laicos Iapse" perteneciente al Departamento de Psicología Social de la Universitat Autónoma de Barcelona. Finalmente, queremos también mostrar nuestro agradecimiento a quienes evaluaron este artículo, cuyos comentarios nos han posibilitado mejorar enormemente este artículo.

\section{Referencias Citadas}

Contreras Gatica, Y. y P. Palma Calorio 2015. Migración latinoamericana en el área central de Iquique: Nuevos frentes de localización residencial y formas desiguales de acceso a la vivienda. Anales de Geografía de la Universidad Complutense 35 (2):45-64.

Coulon, A. 1987. La Etnometología. Cátedra, Madrid.

de Miguel Álvarez, A. y E. Palomo Cerdeño 2011. Los inicios de la lucha feminista contra la prostitucion: Políticas de redefinición y políticas activistas en el sufragismo inglés. BROCAR. Cuadernos de Investigación Histórica 35:315-334.

Garfinkel, H. 1967. Studies in Ethnomethodology. Prentice-Hall, New Jersey.

Gimeno, B. 2012. La Prostitución: Aportaciones para un Debate Abierto. Ediciones Bellaterra, Barcelona.

Graça, M. y M. Gonçalves 2015. Conhecimento, prática e ética: Os desafios da investigação-ação em contexto de prostituição feminina de rua*. Revista Crítica de Ciências Sociais 108:135-156.

Heritage, J. 1991. Etnometodología. En La Teoría Social Hoy, editado por A. Giddens y J. Turner, pp. 290-350. Alianza Editorial/ Conaculta, México D.F.

Íñiguez, L. 2006. Análisis del Discurso. Manual para las Ciencias Sociales. Segunda edición, EDIUOC, Barcelona.

Juliano, D. 2004. Excluidas y Marginales. Una Aproximación Antropológica. Cátedra, Barcelona.

Juliano, D. 2005. El trabajo sexual en la mira. Cadernos Pagu 25:79-106.

Juliano, D. 2017. Tomar la Palabra. Mujeres, Discursos y Silencios. Ediciones Bellaterra, Barcelona.

Lamas, M. 2016. Feminismo y prostitución: la persistencia de una amarga disputa. Debate Feminista 51:18-35.

Martínez-Guzmán, A., A. Stecher y L. Íñiguez-Rueda 2016. Aportes de la psicología discursiva a la investigación cualitativa en psicología social: análisis de su herencia etnometodológica. Psicología USP 27 (3):510-520.
Ministerio del Interior 1891. Ley sobre organización y atribuciones de las municipalidades. Publicada en Diario Oficial de la República $N^{\circ} 4.111$, del 21 de diciembre de 1891, Chile.

Observatorio de Políticas Públicas en VIH y SIDA 2012. Investigación de Monitoreo y Valoración de la Política Pública de Prevención y Atención Integral del VIH y SIDA en Población de Mujeres que Ejercen el Comercio Sexual. Fundación Savia, Santiago de Chile. http://www.fundacionsavia.cl/media/uploads/ docs/INVESTIGACION_COMERCIO_SEXUAL_-_2012.pdf (25 de julio de 2016)

Oñate Rojas, D. 2013. Esperan una ordenanza para regular el comercio sexual. La Estrella de Iquique, p. 2. http://www.estrellaiquique.c1/ impresa/2013/03/24/full/cuerpo-principal/2/ (15 de abril del 2016).

Pávez, J. 2011. Comunidad e inmunidad sexual. A propósito del intercambio económico-sexual en una historia social de Chile (siglos XIX-XX). En Capitalismo y Pornología. La Producción de los Cuerpos Sexuados, editado por J. Pávez y L. Kraushaar, pp. 105154. Qillqa, San Pedro de Atacama.

Pheterson, G. 2000 [1996]. El Prisma de la Prostitución. Traducido por R. Heredero y Y. Azize Vargas. Talasa, Madrid.

Rondón, A. 2012. Vecinos salieron a la calle para protestar por la prostitución callejera. La Estrella de Iquique, p.12. http://www. estrellaiquique.cl/impresa/2012/11/12/full/cuerpo-principal/12/ (20 de julio 2016).

Spink, P. 2005. Replanteando la investigación de campo: relatos y lugares. Athenea Digital. Revista de Pensamiento e Investigación Social 8:1-9. http://atheneadigital.net/article/download/238/238 (13 marzo 2016)

Taylor, S. y R. Bogdan 1996. Introducción a los Métodos Cualitativos de Investigación: La Búsqueda de Significados. Paidós, Barcelona.

Walkowotz, J. 1993. Sexualidades peligrosas. En Historia de las Mujeres en Occidente, editado por G. Fraisse y M. Perrot, tomo 4, pp. 369-404. Taurus, Madrid.

Wolf, M. 1982. Sociologías de la Vida Cotidiana. Cátedra, Madrid. 


\section{Notas}

${ }^{1}$ En relación a esto, como punto de partida $-\mathrm{y}$ tal como han visto- denominaremos esta actividad como prácticas profesionales del sexo hasta definir su actividad "desde adentro" del contexto local de acción.

${ }^{2}$ Si bien Garfinkel denomina este concepto como "miembro competente', utilizaremos indistintamente las denominaciones "membrecía competente" y "actriz competente" como estrategia de uso para un lenguaje menos sexista.

${ }^{3}$ Nuestro trabajo de campo siguió las directrices éticas marcadas por la Universitat Autònoma de Barcelona (UAB) y está enmarcado en un Programa de Doctorado español. En España, las investigaciones en ciencias sociales no disponen de una regulación que obligue a la autorización por parte de un Comité de Ética. Por el contrario, se hace referencia únicamente al "código de buenas prácticas" de cada centro de investigación (en nuestro caso la UAB) (http://www.recerca. uab.es/ceeah/docs/CBPC-cat.pdf). Este código requiere la obtención del consentimiento informado, confidencialidad y no poner en riesgo a los participantes de la investigación".

${ }^{4}$ Son lugares populares en Chile donde se bebe principalmente cerveza de barril. Algunos se distinguen porque ofrecen como servicio la compañía de una mujer mientras está en el local.

${ }^{5}$ Monumento acerca de los soldados caídos en la Guerra del Pacífico y que está ubicado en la frontera norte de Iquique. 
